\title{
DE CÓMO UN RÉGIMEN DE GESTIÓN SE CONVIRTIÓ EN IMPERATIVO CATEGÓRICO DE LA UNIVERSIDAD ${ }^{1}$
}

Por:

José Hleap Borrero

Profesor de la Escuela de Comunicación Social

Universidad del Valle

johleap@yahoo.com

\section{Resumen:}

En este artículo se busca indagar, poniendo en juego las ideas de autonomía, universalidad y convicción, la manera sutil como se ha ido transformando el ethos de las universidades públicas en América Latina, pasando del concepto de bien público de prestación estatal ligado tanto a la crítica del conocimiento - de sus contenidos y de sus usos - como a la búsqueda de caminos propios para el desarrollo latinoamericano -, y por tanto a una idea del vivir bien en instituciones justas-, a la de servicio público, función instrumental que desactiva la comunidad académica, su autoridad y dignidad, para otorgársela a un régimen de gestión (procedimientos y controles ligados a conceptos abstractos de eficiencia y eficacia, originados en el mundo empresarial) que funge como imperativo categórico del nuevo ethos universitario.

Palabras claves: régimen de gestión, ethos universitario, políticas de conocimiento y Universidad.

\begin{abstract}
:
This article wants to inquire, taking the ideas of autonomy, universality and conviction, the subtle way in which has been converted the public college's ethos in America Latina, passing from the concept of public good of state benefits - bounded as much to the critical of knowledge as to the search of own ways for the LatinAmerican development, and therefore to an idea of good living in just institutions to a conception of public service, instrumental function that disables the academic community, its authority and dignity, to confer it to a management regime that serves as a categorical imperative of a new college ethos.
\end{abstract}

Key words: management regime, college ethos, knowledge policies and College. 


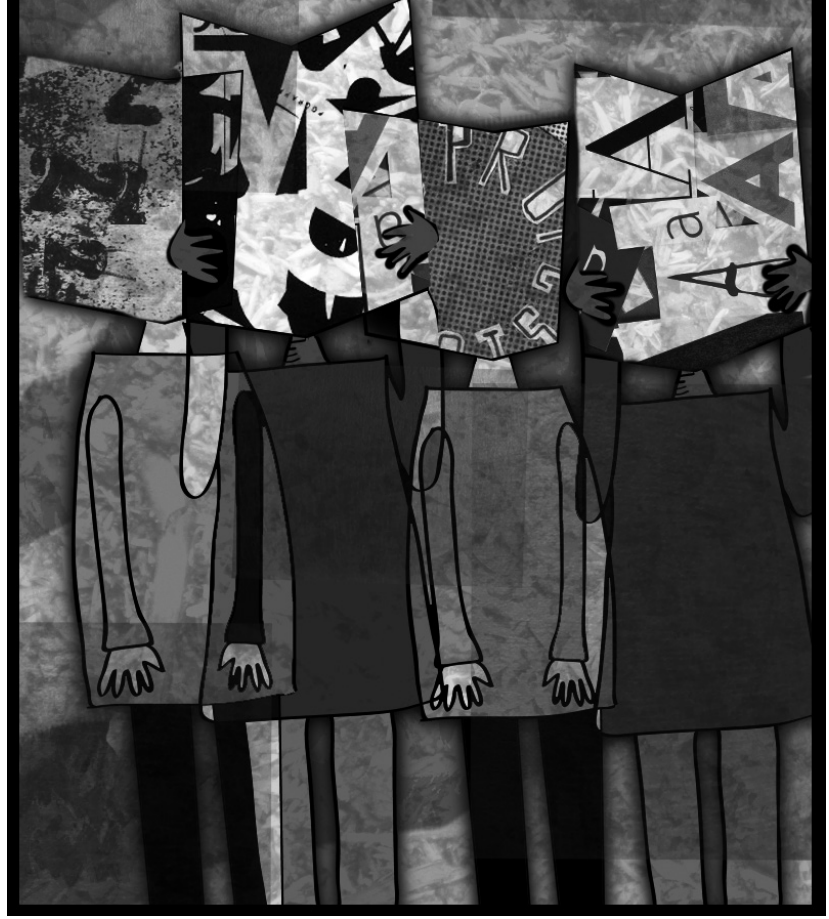

Allí donde un objeto de la voluntad es puesto como fundamento para prescribir a la voluntad la regla que ha de determinarla, esta regla no es más que simple heteronomía, y el imperativo se halla condicionado del siguiente modo: hay que obrar de tal o cual modo si se quiere este objeto o porque se quiere este objeto. Por consiguiente, no puede nunca mandar moralmente, o lo que es igual, categóricamente. (Emmanuel Kant, 1785)

\section{La vida institucional}

En las últimas tres décadas (1980 a 2011), se ha consolidado en América Latina un cambio dramático en el ethos universitario, particularmente evidente en las Universidades Públicas. Retomo aquí un uso del término "ethos" que aúna el sentido más antiguo - "morada", "lugar donde se habita"- con el de "fundamento de la praxis"modo de ser o "carácter"- para nombrar la dimensión institucional constituida por un conjunto de emplazamientos, mitos, rituales y vínculos que definen y legitiman, por períodos significativos, la vida universitaria, incluso con relativa autonomía de las normativas vigentes y de los propósitos explícitos de la institución.

Como plantean Arocena y Sutz (2000:4) "la Universidad Latino-americana constituye una institución original, fruto de una construcción histórica específica, cuya tradición la liga tanto a la crítica del conocimiento — de sus contenidos y de sus usos - como a la búsqueda de caminos propios para el desarrollo latinoamericano." Las Ideasfuerza (Bloch, 1977) que conformaban tanto la imagen² interna como externa de la universidad pública latinoamericana antes de la década de los ochenta (obviamente como rasgo dominante pero con especificidades notables en cada país) eran las de autonomía del pensamiento (independencia respecto a otros poderes desde el "uso de la razón"), expresada en forma de juicio crítico frente al status quo ${ }^{3}$, autogobierno, financiación estatal (carácter de "bien público") y vocación de "universidad de investigación" que articulaba la docencia con la investigación y la extensión como pilares de la "comunidad académica" universitaria. Si se tiene en cuenta que gran parte de las naciones latinoamericanas se caracterizaban, bien entrado el siglo veinte, por ser sociedades cerradas hegemonizadas por unas cuantas familias (castas) y con un férreo control ideológico por parte de la iglesia católica, la conquista de un espacio social relativamente autónomo al confesional y al gubernamental ha sido muy poco valorada en la historia de la gestión social del conocimiento en nuestros países.

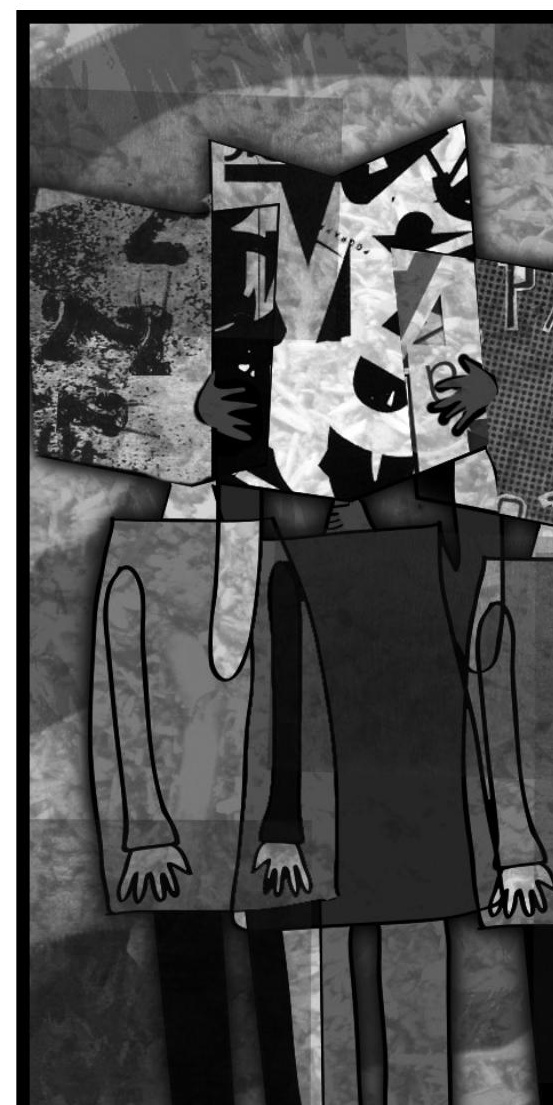


Durante las primeras décadas del siglo XX, en una costosa, lenta y tardía consolidación, la marcha del humanista "libre pensador", miembro de una élite intelectual con autoridad cultural y de abolengo, por la ruta del intelectual con formación superior fue sirviendo -incluso con su propia connivencia- a la institución de las disciplinas sociales y humanísticas en las universidades latinoamericanas (Neiburg, Plotkin y otros, 2004). Con un breve período de hegemonía del maestro universitario como "intelectual" cultivador de un "saber docto" enciclopédico, la docencia universitaria toma la forma de una modalidad específica de trabajo en las distintas profesiones y luego, bajo la figura del docente-investigador ${ }^{4}$, se convierte en una opción profesional en sí misma, aunque "el cultivo exclusivo de la docencia universitaria o del trabajo científico seguirá siendo, aún al final del período, una excepción" (Altamirano, 2004:36). De este transito pervive hasta la década de los ochenta, aunque cada vez más desdibujado, el carácter de compromiso personal con la crítica (ahora bajo el mandato de la ciencia) que tenía el aura del intelectual. La expansión de la educación superior en los años sesenta en prácticamente todos los países de América Latina acompaña -y en algunos casos, responde- a la presión ejercida por la modernización de los países y el desplazamiento (voluntario o forzado) del campesino empobrecido a la ciudad ${ }^{5}$, en donde se hicieron visibles los conflictos y contradicciones urbanas así como la potencial “ingobernabilidad” de la masificación y fragmentación sociocultural que ahora la poblaba. Las luchas por la democratización y ampliación del acceso a la universidad son reivindicadas por los movimientos estudiantiles de la época como garantías de su carácter público y la vinculación directa con otras luchas sociales (movimiento campesino, lucha sindical, movilización indígena) aseguraría el espíritu crítico y contestatario de la formación, alentado por la experiencia cubana. Esta conflictividad interna, cuya expresión externa se daba en términos de rompimiento del "orden público" y de solidaridad activa con luchas revolucionarias, se sumaba a la no adecuación funcional de la formación universitaria con el mercado de trabajo, haciendo de la universidad pública el sospechoso habitual de los gobiernos de turno.

Ante esta conflictividad, "la preparación para las profesiones transita del ethos público hacia la búsqueda de un ethos corporativo, perfilado por las demandas de un reducido mercado ocupacional que requiere una racionalidad instrumental y eficiente para el desempeño de las profesiones en las corporaciones privadas" (Mollis, 2003:207). La "profesionalización" del pensamiento de lo social, su separación en "especialidades" que luego tomaron el cuerpo de carreras autónomas al ritmo de los problemas sociales suscitados por el rápido proceso de modernización de Latinoamérica y las transformaciones en la organización del conocimiento lideradas por las metrópolis intelectuales de la época, ubicaron el aporte de la universidad, bajo el auspicio de las "organizaciones multilaterales", en el campo de la políticas públicas y de la gobernabilidad bajo la rúbrica del "experto" neutral que hacía una mediación "técnica" en los conflictos. La orientación que sirve de fundamento para este "papel” del profesional universitario fue el positivismo entendido, según propone Altamirano (2004: 36), como "una cultura, cultura intelectual más bien ecléctica, aunque, globalmente, de espíritu más spenceriano que comteano. 
El rasgo central de esta cultura fue hacer de la ciencia el intérprete privilegiado de la realidad, y de las ciencias del mundo natural el modelo de referencia para las ciencias del mundo social".

Diríamos que en su desarrollo posterior, la influencia de modelos teóricoconceptuales de tipo funcionalista y de un estructuralismo marxista dogmático dibujan un panorama para las ciencias sociales que se tensa entre las lecturas parciales de las realidades nacionales apoyadas en datos empíricos y localizados en problemáticas sociales concretas y la lectura deductiva interesada en situar en estas realidades los conceptos que justificaban la denuncia de la dominación y la crítica ideológica. A comienzos de los años '70, afirma Jesús Martín Barbero (2003:45), "las ciencias sociales libran en Latinoamérica una particular lucha a la vez contra la fascinación cientifista de un funcionalismo omnipresente y contra la inercia de una dogmática y una escolástica marxistas", que se manifiesta como "el esfuerzo por romper la hegemonía de un positivismo que separa la forma legitimada de lo conocible del contenido de lo vivido socialmente".

Habría que establecer también que los replanteamientos conceptuales tanto en los límites disciplinares como en las perspectivas epistemológicas y éticas de generación de conocimiento, no llegan a transformar profundamente la organización y la vida institucional de las universidades públicas, como sí lo hace la precariedad, el estado permanente de zozobra interna, la indolencia, burocratización, patrimonialismo e ensimismamiento que han sido cómplices del estado de crisis al que ha sido paulatinamente confinada.

En un escenario dominado por la recesión e inflación, la década del ochenta mostró en América Latina las consecuencias de la ofensiva socioeconómica e ideológica del neoliberalismo en la región, con el inicio de los programas de apertura y ajuste económico y la acentuación de la crisis social. La llamada "década perdida", que fue también la década de la democratización de algunos regímenes políticos de la región (Chile, Argentina, Uruguay, Paraguay, Nicaragua, Brasil), marca el momento definitivo en el tránsito de la "universidad de investigación" a la "universidad corporativa”, bajo el mandato del "ajuste administrativo" ante la precarización de los recursos para la Educación Superior.

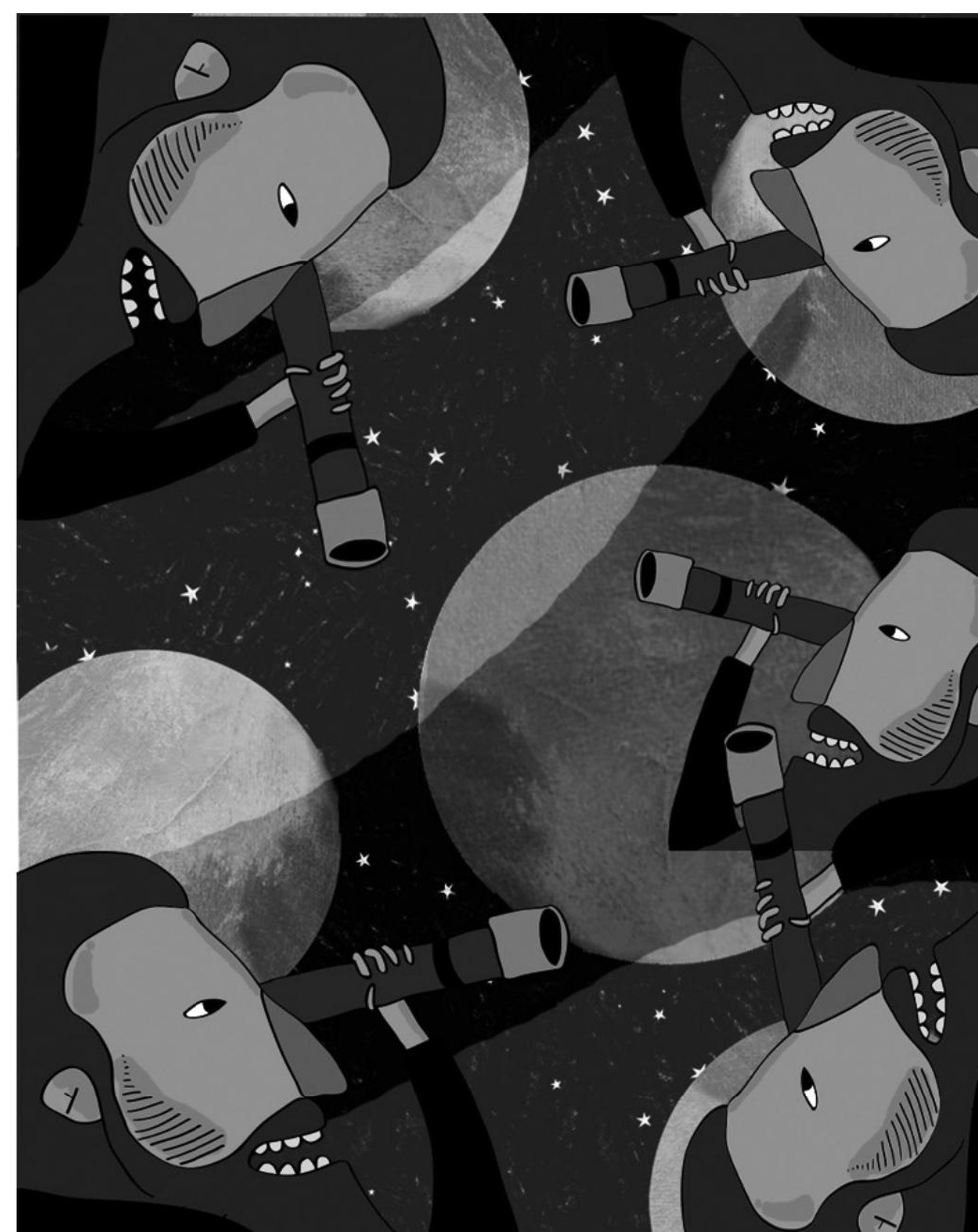


Por eso es preciso recordar hoy, cuando estamos en Colombia ad portas de una nueva reforma a la legislación de la educación superior, que "en términos sociales, la restricción de la autonomía de las universidades y la amplitud de las facultades del Estado no lograron mejorar la calidad, ni controlar el crecimiento indiscriminado de programas e instituciones de dudosa calidad e incluso origen. Por el contrario, ese desconocimiento de las universidades como comunidades académicas y su percepción como simples prestadoras de un servicio restringieron la posibilidad de fortalecerlas como espacios públicos" (Villamil, 2005:233).

En la década de los noventa se consolidó en las universidades de América Latina el ethos tecnocrático (Estévez, 2006) que en Colombia plasma la Ley 30 de 1992, siguiendo las recomendaciones que en materia de Educación Superior formula el Banco Mundial, en donde "se busca desplazar la modalidad de coordinación de los sistemas desde el actual régimen con su inadecuada mezcla de elementos de coordinación burocrática, corporativa y política hacia una coordinación basada en nuevas formas de financiamiento y la adopción de controles de calidad y eficiencia. (Brunner et al, 1994: 40). La estrategia propuesta por el Banco Mundial se fundó en cuatro elementos esenciales:

(I) Estimular una mayor diferenciación de las instituciones, incluyendo el desarrollo de instituciones privadas; (II) proporcionar incentivos a las instituciones públicas para que diversifiquen sus fuentes de financiamiento. Incluyendo una coparticipación de los alumnos en la recuperación de costos y vinculando el financiamiento público estrechamente al desempeño; (III) redefinir el rol del gobierno en relación a la educación superior, y (IV) introducir políticas explícitamente diseñadas para dar prioridad a objetivos de calidad y equidad. (Brunner et al, 1994: 70)

Este ethos tecnocrático introduce en el corazón mismo de las universidades, en sus modelos de gestión y políticas de conocimiento, la lógica empresarial en la cual "el saber se mide con el lenguaje de las finanzas, se calcula a través de indicadores de rendimiento y de certificados y diplomas entregados en tiempo y forma con mayor valor de mercado; se representa en la formación de recursos humanos cuando, al mismo tiempo, las humanidades van perdiendo gradualmente sus recursos. Nuestras universidades tienen alterada su identidad como instituciones de los saberes hacia la construcción de una nueva identidad que las asemeja al supermercado, donde el estudiante es cliente, los saberes una mercancía, y el profesor un asalariado enseñante" (Mollis, 2003: 204).

La neutralidad valorativa, la eficiencia operativa y el prurito de la innovación no se quedan solo en el terreno de la administración de la institución universitaria si no que operan, sin someterla a debate o cuestionamiento, una política de conocimiento: La pretensión de un conocimiento descarnado (sin sujeto, acción o pasión), su reducción al algoritmo de un "hacer" (por ejemplo, la idea de "pasos metodológicos" o de "competencias cognitivas"), y adecuación a estándares, programas nacionales de investigación y convocatorias que reducen lo pensable a lo administrable.

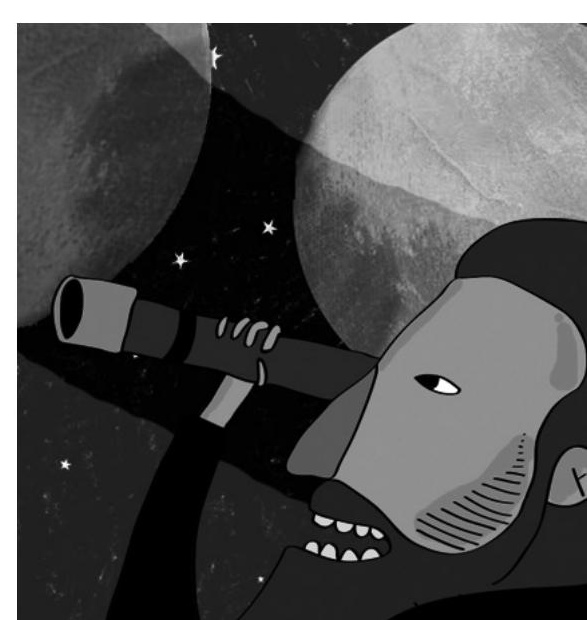


En este "estado de gestión" pareciera que las tres crisis que afectan la Universidad según Boaventura de Sousa Santos (2005), la crisis de la hegemonía, la crisis de legitimidad y la crisis institucional, se "resuelven" - como temía el autor- en "una auténtica reconversión industrial de la Universidad, que destruirá las universidades clásicas, fragmentando los estudios en su esfuerzo por adaptarlos a las demandas del mercado, pero ignoramos si será capaz de construir en su lugar una Universidad duradera. Más bien, pensamos que la Universidad que hemos conocido, con todas sus carencias, está tocando su fin y que, en el mejor de los casos, será sustituida por una red compleja de ofertadores de servicios cognitivos, de servicios de formación y de investigación, cuyas potencialidades todavía desconocemos" (Galcerán Huguet, 2007: 94). Sin hacer concesiones a la defensa a ultranza de ciertos intereses mezquinos que han patrimonializado la Universidad pública, considero de vital importancia para América Latina el reconocimiento y cuidado del aporte que a nuestras sociedades ha hecho la institución de una "comunidad académica" regida por sus propios principios de probidad, autoridad, organización y por explícitos mecanismos de iniciación, formación y acceso (al menos nominalmente) y, por tanto, resistente a injerencia de otros poderes e intereses. Se ha podido apreciar no solo en

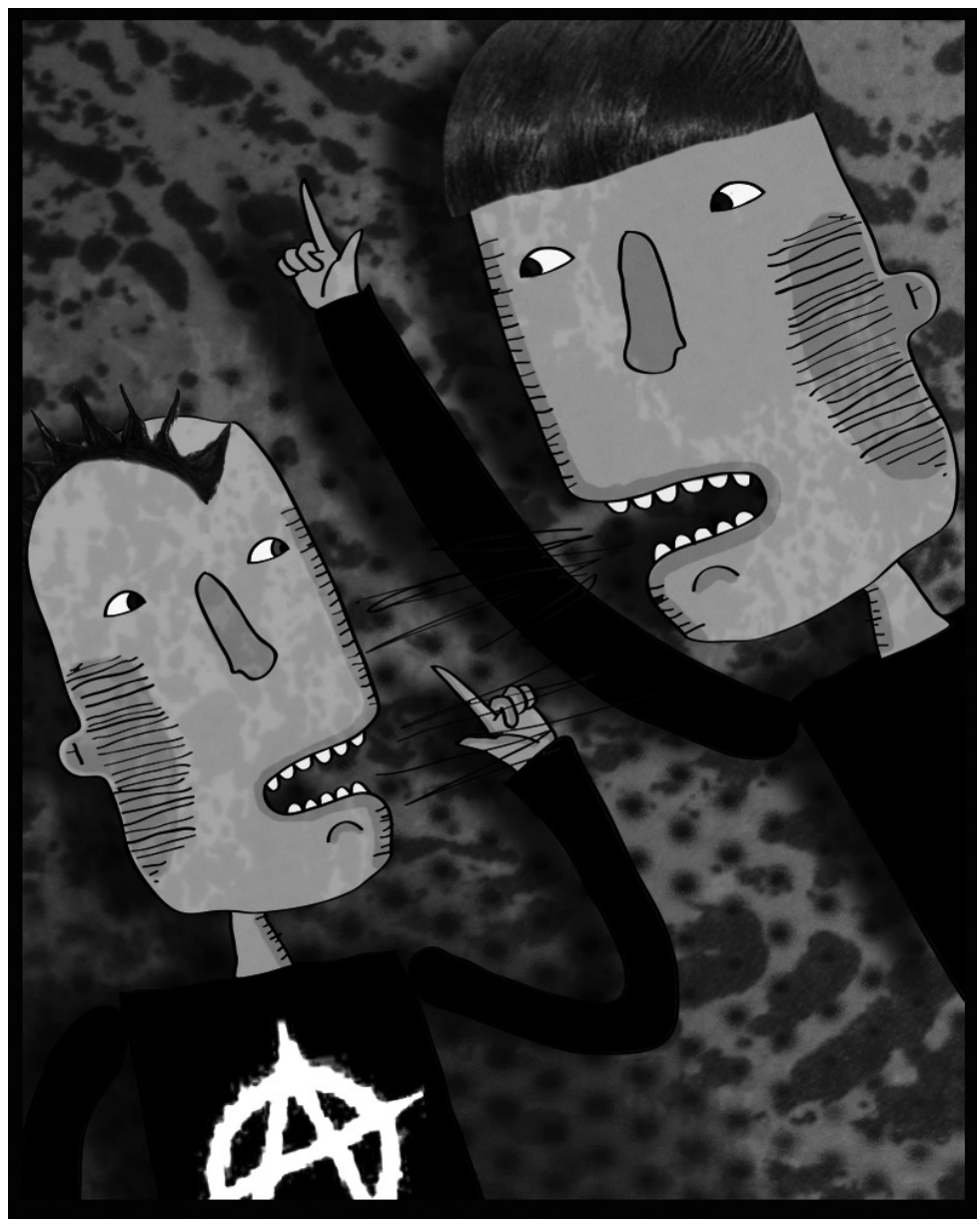
la formación de un número significativo de profesionales competentes en su campo específico de ejercicio, lo es en la generación de políticas públicas y de fortalecimiento y organización de sectores subalterizados.

También en que sus egresados, en conjunto, han podido agenciar - con disímiles resultados- perspectivas renovadoras respecto al desarrollo y a las formas dominantes de conducción de estas sociedades (la lucha por la democratización, por ejemplo) y lo es especialmente por ser prácticamente la única entidad productora de un conocimiento contextualizado sobre nuestra realidad:

La "idea latinoamericana de universidad" es la de una institución autónoma, cogestionada por la propia comunidad universitaria, en la cual la representación estudiantil es un factor de democratización interna y de apertura externa, la cual vincula a la universidad con los sectores postergados, convirtiéndola en palanca de democratización social y cultural.

De la idea a la realidad la distancia nunca fue pequeña, pero tampoco fue pequeña la gravitación de la idea sobre la realidad (Arocena y Sutz, 2000:76). 
Afincados en el examen de lo que ha sido esta idea de universidad y de su autonomía, es necesario preguntarse por nuestra responsabilidad como docentes en la creación del engendro actual. Comparto con Harold Galvis Parrasi el llamado a que "desde el Ethos universitario que nos es propio, que no emana de ningún formalismo, se hace necesario e imperioso pronunciarnos, pues asombra ver cómo lo necrótico administra y genera instrumentos formales y legales que desdicen de la sublime tarea del pensar y del formar" (Galvis, 2011:2). Como plantean Arocena y Sutz (2000:4) "sin nuestras universidades actuando como generadoras activas de conocimiento, demasiados problemas específicos de la región quedarán en el limbo de las preguntas formuladas por nadie”.

\section{El régimen de gestión, el caso- o el ocaso- de la Universidad del Valle}

Las prácticas materiales dispuestas por el sujeto en el contexto de la institución (sea que se trate de arrodillarse para orar o de cambiar los pañales para algunos) forman procesos de producción de su propia subjetividad. El sujeto es activo, engendrado de manera reflexiva por las vías de sus propios actos. Enseguida, las instituciones proporcionan sobre todo un lugar discreto (el hogar, la capilla, el salón de clase, el taller) donde se monta la producción de la subjetividad. Las diversas instituciones de la sociedad moderna deberían considerarse como un archipiélago de fábricas de subjetividad (Hardt, 2005:31).

La Universidad del Valle: un caso de reconstrucción institucional (2006), escrito por su actual Rector Iván Enrique Ramos Calderón, es un documento que reposa en "Colombia Aprende" la "red del conocimiento" del Ministerio de Educación Nacional, como ejemplo de superación de "la situación de crisis académica y administrativa vivida por la Universidad en los años 90's”. En este documento se nombra puntualmente el "contexto institucional" en el que sobreviene la crisis: La Ley 30 de 1992 que "reorganiza el Servicio Público de Educación Superior”; la Ley 29 de 1990 o ley de Ciencia y Tecnología que bajo la rúbrica del "fomento" establece las bases para "la creación de nuevas formas organizativas que permitan hacer ciencia y tecnología, a través de alianzas entre el sector público y privado"; el Decreto 1444 de 1992 que instituye un nuevo régimen salarial y prestacional para los profesores de la Universidades Públicas; la Ley 100 de 1993 que instaura el sistema nacional de Seguridad Social "con sujeción a los principios de eficiencia, universalidad, solidaridad, integralidad, unidad y participación” y la Ley 26 de 1990 o Ley de Estampilla Pro-Universidad del Valle, que le genera recursos adicionales a la institución.

Aunque en el documento se relaciona explícitamente este conjunto de medidas legales con "una década de grandes transiciones ${ }^{6}$ para las instituciones de Educación Superior y, en especial, para las Universidades", la explicación de la crisis, así como su "solución", solo se refieren al manejo administrativo, creando la ilusión de que la crisis se reducía a un problema de (mala) gestión y que, por tanto, una juiciosa implementación del conjunto de normas descritas, una administración ajustada a la lógica empresarial, eufemísticamente llamada "normalidad académica", conduciría a su superación. 
Aunque en el Foro público sobre la crisis de la Universidad y en muchos documentos de la época se estableció lo que expresó adecuadamente Boaventura de Sousa Santos respecto al conjunto de Universidades Públicas en el mundo, que la crisis institucional era el "resultado de la contradicción entre la reivindicación de la autonomía en la definición de valores y objetivos de la universidad y la presión creciente para someterla a criterios de la eficiencia y la productividad de naturaleza empresarial o de responsabilidad social" (Santos, 2005: 24), la Universidad del Valle recorrió jubilosa el tránsito al ethos tecnocrático, "para ajustarse a las exigencias de la administración y la educación contemporáneas"(Ramos,2006: 2), sin "preguntarse por las causas reales de esta crisis: "El análisis de estas revelará que la persistencia de la crisis institucional fue el resultado de que se condensaran en ella el agravamiento de las otras dos crisis, la de hegemonía y la de legitimidad" (Santos, 2005: 29).

¿Qué ha pasado entre tanto con el académico que, en aras de no entregar a la lógica administrativa la gestión de la U. asumió como propio este trabajo, ocupando cargos de dirección en su valioso tiempo altamente calificado para la docencia y la investigación? Con indignación ante la imposición de un "código de ética" para los profesores universitarios por parte de la dirección universitaria, un docente manifestaba que "lo lamentable es que quienes así obran son igualmente nuestros colegas, docentes, personas muy calificadas que han pasado por diferentes niveles de la dirección universitaria, incluso han sido representantes profesorales, ¡¿quien habría de creerlo?!, y que hoy, por las lógicas políticas son nuestros directivos, aunque no necesariamente los más representativos. ¿Qué ha pasado? ¿Los obnubila el poder? Parece ser que, una década después de la crisis administrativa y financiera de la Universidad del Valle, asistimos a la muerte del ethos universitario público a expensas de la "soberanía del funcionario" (Galvis, 2011: 9). La respuesta a estas inquietudes se encuentra, a mi parecer, en la frase de Michael Hardt que encabeza este punto, la subjetividad que emerge en estas instituciones refuncionalizadas.
El modelo de universidad resultante de las medidas "administrativas" implementadas durante estas dos décadas en la Universidad del Valle es, como lo precisaré más adelante, la institución del medio subjetivante propio de las sociedades de control (Deleuze), fundado en la modulación permanente del compromiso subjetivo, en medio de "la declinación de la autoridad simbólica patriarcal"(Zizek, 2004:365), donde la ilusión de poder gobernar las propias vidas, de diversificar las experiencias y compromisos nos hace administradores eficientes y normalizados de nosotros mismos: "Si en el capitalismo industrial la subjetividad debía aparcarse en las taquillas de la fábrica, en el capitalismo contemporáneo debe manifestarse, debe ser puesta a trabajar (Corsani, 2007:48).

Considero que el término "control", que insinúa un poder ejercido desde afuera, no es el más adecuado para estas sociedades en las que la modulación incita el hacer y cuya clave es la gestión, incluso de "si". Me parece más adecuado hablar de "régimen de gestión". En la evidencia del "buen funcionamiento" institucional desde la aparentemente neutral "lógica administrativa”, se desliza la eficacia de la modulación que afecta a la subjetividad en su proceso de constitución, dentro de particularidades de su propia producción ${ }^{7}$ :

La concepción de Valor no es algo que fluya desde la comunidad o sociedad misma, es impuesta y explicitada por escrito, como para que a nadie se le olvide. Ahora toca ser líder por obligación, puntual, con recta conducta, justo e imparcial, portarse bien, ser moral, eficaz, eficiente, probo, rápido y competente. ¡Qué bien! Ya se impondrá por resolución que tomemos un curso "voluntario" de ¡Justo a Tiempo! con la promesa de que nuestra foto aparecerá en la página web de la universidad encabezando la lista de los mejores funcionarios que lograron las metas en el respectivo período académico. Ello será digno de admiración dado el buen ejemplo de tan excelentes funcionarios (Galvis, 2011:6). 
Se trata de la creación del "pequeño sujeto tecnocrático", el "esclavo discrecional” del que hablara Wilhelm Reich (1981:22) o el "sujeto perverso polimorfo" del que habla recientemente Zizek (2001:264). La configuración de este sujeto, el cual no sólo lo encontramos entre los docentes si no que campea entre los estudiantes, se inició mucho antes de la "década de la crisis". Pertenece al ejercicio de la gubernamentalidad (Foucault), una especial articulación entre soberanía, disciplina y regulación, como técnica de gobierno. La "sociedad de control” sería el actual régimen de gubernamentalidad; "entramos en sociedades de control que ya no funcionan por encierro sino por control continuo y comunicación instantánea. (Deleuze, 2005:18).

Hardt (2005:32) afirma que "el control es así una intensificación y una generalización de la disciplina, donde las fronteras de las instituciones han sido violadas, vueltas permeables, de tal suerte que ya no se distingue el afuera del adentro". Lo que hemos visto con el paulatino desvanecimiento de la autonomía universitaria, la del pensar y actuar como académicos, es precisamente la destrucción sistemática del ethos universitario mediante la incorporación (en los funcionarios, profesores, estudiantes y también en la “opinión pública”) de la lógica empresarial (la neutralidad valorativa, la eficiencia operativa, la dirección ejecutiva, la competencia feroz y el prurito de la innovación) puesta "como fundamento para prescribir a la voluntad la regla que ha de determinarla”(en palabras de Kant); dándole el carácter de imperativo categórico (incondicionado, válido universalmente y del orden de la intención moral) cuando se trata de un "simple medio para otro propósito" (condicionado, con validez contingente, instrumental) que, como sentencia el mismo Kant en la cita con la cual encabezo este escrito, "no es más que simple heteronomía".

El proceso de incorporación de este régimen de gestión como imperativo categórico de la universidad se inicia con una "crisis de investidura" (Zizek, 2004: 119), con la pérdida de la identidad simbólica del académico en función de su identificación como "experto" y luego como "funcionario". Del intelectual crítico al docenteinvestigador se dio un paso de incorporación institucional; del docente investigador al "asalariado enseñante" (Mollis, 2003: 204) se da la destitución simbólica de la crítica, del pensamiento y de la autonomía. Ya Brunner planteaba, en un lenguaje tecnocrático claramente tendencioso, la "ideología" que había que destituir según las recomendaciones del Banco Mundial para la educación Superior:

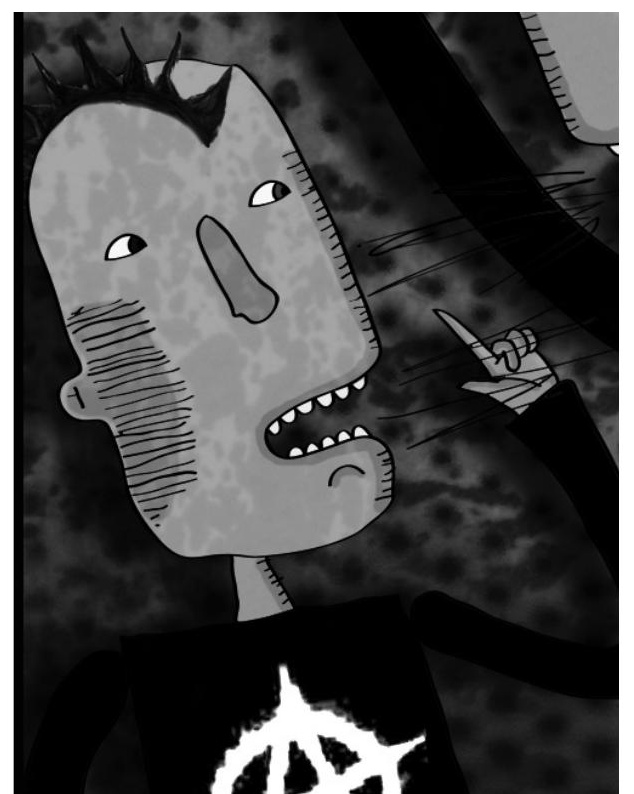

La ideología tradicional de los sistemas de educación superior especialmente en su sector público, que se identifica fuertemente con un mecanismo de asignaciones automáticas, un repudio a la competencia y a cualquiera forma de coordinación con participación de los mercados, modalidades burocrático-estatales de regulación, isonomía salarial y la aspiración a una baja diferenciación entre las instituciones del sistema. Esta ideología tiene una expresión especialmente aguda en el caso de los sindicatos docentes de las universidades públicas y encuentra sus máximas expresiones simbólicas en torno a cuestiones tales como el rechazo al cobro de matriculas, la defensa de una suerte de autarquía de esas instituciones, el alegato en favor de formas de cogobiemo interestamental, etc. (Brunner et al, 1994: 67) 
Esta destitución simbólica del académico está bastante presente en los imaginarios reiterados por los medios de comunicación (la burla hollywoodense al "nerds" o al "profesor chiflado" ) y practicados por los actuales "estamentos" de la Universidad del Valle (y de las universidades públicas, en general), para los cuales cada vez más no son los argumentos y las ideas, las tradiciones investigativas, la dirección colegiada, la formación exigente y la probidad intelectual las que pesan a la hora de las decisiones sobre el curso de la vida universitaria, si no la capacidad de presión (y "tropel"), el reconocimiento de la clientela editorial y credencialista (Bermejo, 2011) y, sobre todo, la conexión con poderes extrauniversitarios (políticos, económicos -especialmente financieros- o de redes mundiales de experticia).

En algunos casos el deterioro de la investidura simbólica del docente universitario ha llegado al límite de la burla, la agresión física y la amenaza (“...un grupo de encapuchados ingresó a un salón de clase para arengar a los estudiantes y el profesor que dictaba la clase los conminó a salir. Ante este hecho los encapuchados profirieron epítetos y amenazas contra el profesor, circunstancia que fue neutralizada por estudiantes que salieron en defensa del docente". Universidad delValle, Comunicado de la Rectoría, Cali, marzo 30 de 2011). Sin embargo, lo que más destruye la función social del académico es la identificación de la universidad pública - en su conjunto- con la reacción violenta, irreflexiva y rutinaria a los temas y problemas cruciales de nuestras realidades, lo que ha sido agenciado por los gobiernos de turno, los medios de comunicación y la desidia e indiferencia de buena parte de la comunidad universitaria. A esta imagen violenta -ausente de ideas y propuestas- le hace el juego la habitual pedrea, las papas bombas y su sordera al resto de opinión universitaria.

El desconocimiento sistemático de los aportes de la Universidad pública a la región y su permanente estigmatización hacen parte de la presión para que ésta coincida con los requerimientos de la universidad corporativa que se vende como el modelo necesario "para ajustarse a las exigencias de la administración y la educación contemporáneas”. Como propone Marcela Mollis:

"La universidad no sólo produce los conocimientos técnicos y científicos necesarios para el desarrollo del país: sobre todo debe producir saberes necesarios para una construcción democrática, más justa y equitativa; debe inventar saberes que no estén condicionados por los códigos del lucro; debe reconstruir su identidad necesaria para nuestras sociedades desprotegidas de individualistas posesivos que niegan el valor de la cultura porque no cotiza en la bolsa de valores. Si la universidad es considerada un elemento del mercado, no hay espacio para la crítica. La evaluación institucional debe proponerse la profundización de las condiciones de la crítica en la universidad, promoviendo los debates públicos y actuando como agente mediador entre actores, sectores e instituciones, desarrollándose como una acción colectiva crítica de la propia institución tanto en su ámbito interno como en sus relaciones con la sociedad. (Mollis, 2003: 212) 
¿A qué - o quién- le sirve la arrinconada universidad pública actual, que la reforma a la Ley 30 pretende mantener en su identidad alterada? Alain Badiou nos diría que para "preparar una democracia sin sujeto (político). Librar a los individuos a la organización serial de las identidades, o al enfrentamiento con la desolación de su goce” (Badiou, 2008:68). La pregunta por este "vaciamiento" en el conocimiento y por la "pobreza de experiencia" (Benjamin) en la universidad de las sociedades de modulación, debería llevarnos a la deconstrucción crítica de los peligrosos efectos “desfuturizadores" y necróticos de una experiencia abolida, expropiada, por un régimen de gestión que funge como imperativo categórico.

Asumir la fragilidad e importancia que en esta sociedad tiene la existencia de un espacio para pensarla críticamente e imaginarla diferente, para buscar soluciones adecuadas a sus problemas más apremiantes, para formar profesionales que no solo sean competentes en su trabajo, si no que vinculen en su ejercicio la comprensión crítica, el compromiso ético y la creatividad significa defender la universidad pública.

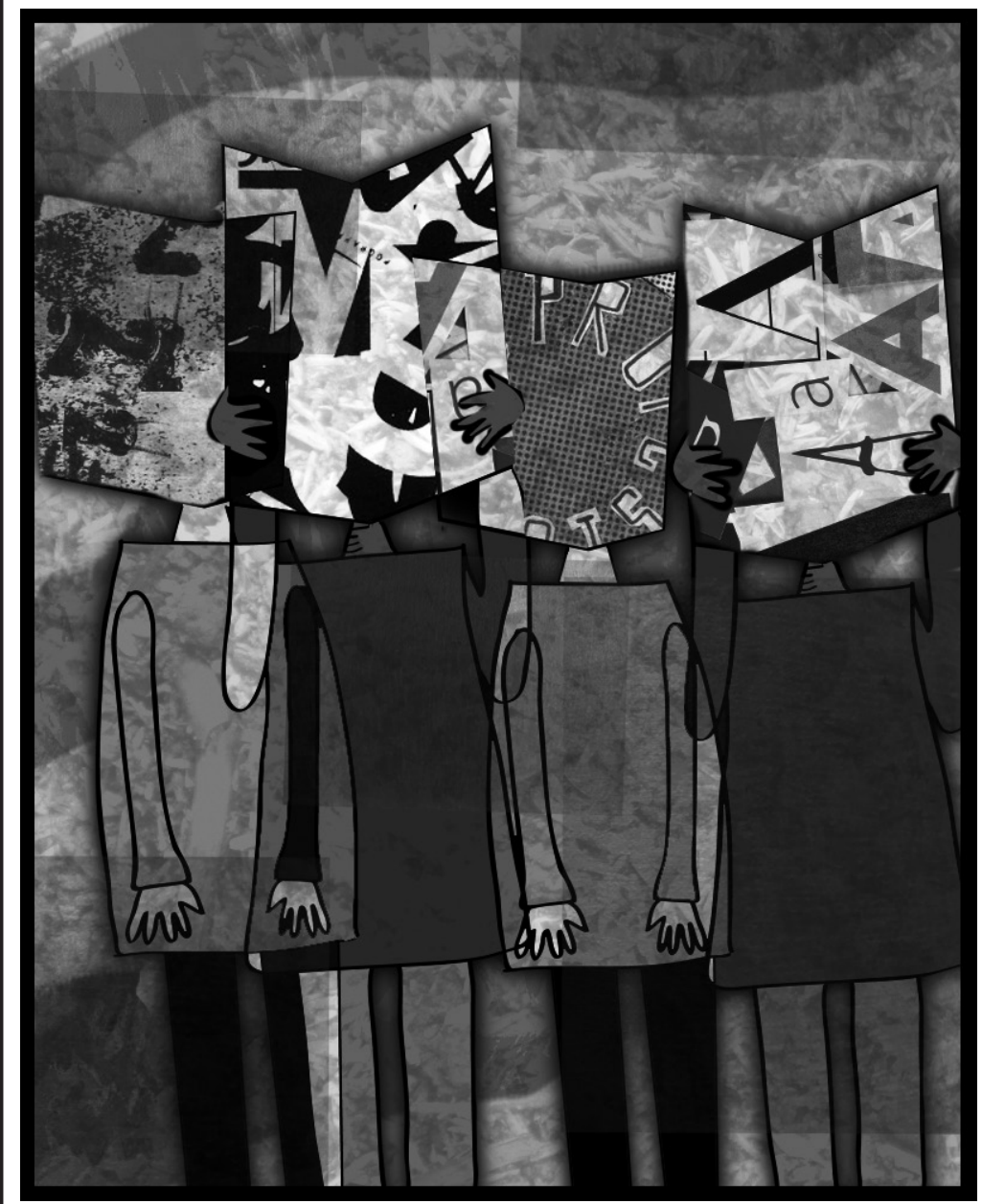

Si asumimos, con Hardt, que la cada vez más delgada frontera que separa el adentro y el afuera de la institución universitaria ha sido violentamente vulnerada por el régimen de gestión, se trata de defender la universidad pública no sólo de las hostiles lógicas externas que pretenden quebrarla, económica y académicamente, con la imposición de un modelo de eficiencia y reducción / reorientación del gasto que cercena toda iniciativa de desarrollo académico, obliga a la docilidad frente a las miopes políticas gubernamentales, reduce significativamente la capacidad investigativa y de intervención social de la universidad y vulnera el derecho de una gran sector de la población a tener educación superior de calidad; es defenderla también frente a ciertas lógicas internas que agenciamos, como aquellas que amparadas en la supuesta representación de intereses populares o sindicales efectúan una patrimonializacíon de lo público - apropiación privada de espacios y recursos de la universidad-, la hegemonía de una lógica del funcionario que se conformó con "administrar la pobreza” o la utilización del deteriorado fuero del espacio universitario para generar inanes espectáculos de fuerza y, la más lamentable y peligrosa de las lógicas internas, la indiferencia cómplice tanto de estos desafueros como de la creciente mediocridad académica y laboral entre profesores, empleados y trabajadores, que sólo la reconocen como un cómodo "trabajadero", de baja exigencia y de infinita permisividad, asimilando lo público a la falta de dueño y de gobierno donde campean los intereses más mezquinos. 
Brunner, José Joaquín (coordinador) et all (1994) Educación superior en América Latina: una agenda de problemas, políticas y debates en el umbral del año 2000. Buenos Aires: CEDES. Disponible en la World Wide Web:

http:/ / 168.96.200.17/ar/libros/argentina/cedes/brünner.rtf

Corsani, Antonella (2004). "Hacia una renovación de la economía política. Antiguos conceptos e innovación teórica”. En Capitalismo cognitivo, propiedad intelectual y creación colectiva. Madrid: Traficante de sueños.

(2005). “Los Fabricantes de Espectáculos del Empleo Discontinuo”. En Producta50, Barcelona: Departamento de cultura y medios de comunicación. www.ypsite.ne.

Deleuze, Gilles (1991) “Postdata sobre las sociedades de Control”. En Christian Ferrer (Comp.) El lenguaje literario, T² 2, Montevideo: Ed. Nordan.

(2005) “Control y Devenir. Entrevista de Gilles Deleuze con Toni Negri”.

En Revista Euphorion, Julio-Diciembre de 2005, edición digital. Medellín: Euphorion.

Estévez, Alejandro M. (2006) Una genealogía de la Tecnocracia. En El poder de los expertos: Para comprender la tecnocracia. Haydée Ochoa

Henríquez y Alejandro M. Estévez (Coordinadores). Maracaibo: Universidad del Zulia, Centro de Estudios de la empresa, Facultad de Ciencias Económicas y Sociales. 65-95.

Foucault, Michel (1999). Estética, ética y hermenéutica, Buenos Aires: Paidós.

Galcerán Huguet, Montserrat (2007) Políticas del conocimiento. Reflexiones sobre la reforma de la Universidad en el capitalismo cognitivo. En Nómadas no 27. Bogotá: IESCO, Instituto de Estudios Sociales Contemporáneos, UC, Universidad Central. Octubre 86-97

Galvis Parrasi, Harold (2011) Del “código de ética” al ethos universitario. El caso de la Universidad del Valle. Cali: Universidad del Valle. Departamento de Administración y Organizaciones. Se encuentra en fenalprou.org.co/documentos/DELCODIGO.pdf

Hardt, Michael (2005) “La sociedad mundial de control”. En Revista Euphorion, Julio-Diciembre de 2005, edición digital. Medellín: Euphorion.

Kant, Immanuel (1980) Fundamentación de la Metafísica de las Costumbres (1785). Madrid: Espasa-Calpe

Martín-Barbero, J. (2003). Oficio de cartógrafo. Travesías latinoamericanas de la comunicación en la cultura. Santiago de Chile: Fondo de Cultura Económica.

(2007) “El conocimiento, primera frontera.” En Metapolítica, Vol. $11 \mathrm{~N}^{\circ}$ 52: 37-44, CEPCOM, México,

Marzo-Abril

Mollis, Marcela (2003) Un breve diagnóstico de las universidades argentinas: identidades alteradas. Buenos Aires: CLACSO. Se encuentra en http: / /bibliotecavirtual.clacso.org.ar/ar/libros/mollis/mollis.pdf

Neiburg, Federico y Plotkin, Mariano (2004). Intelectuales y Expertos. Hacia una sociología histórica del conocimiento sobre la sociedad en la Argentina. En Intelectuales y Expertos. La constitución del conocimiento social en la Argentina. Federico Neiburg y Mariano Plotkin (Comp.) Buenos Aires: Paidós 15- 30

Ramos Calderón, Iván Enrique (2011) Comunicado de la Rectoría. Cali: Universidad del Valle, Rectoría, marzo 30 de 2011 (2006) La Universidad del Valle. Un caso de reconstrucción institucional.

En http://www.colombiaaprende.edu.co/html/mediateca/1607/articles-101882_archivo.pdf

Reich, Wilhelm (1981) Escucha hombrecito. Barcelona: Bruguera

Santos, Boaventura de Sousa (2005) La Universidad en el Siglo XXI. Para una reforma democrática y emancipadora de la universidad. México DF: Universidad Nacional Autónoma de México, Centro de Investigaciones Interdisciplinarias en Ciencias y Humanidades.

Villamil Ardila, Carol (2005) Alcance de la autonomía universitaria en Colombia, 1980-2002 Una reflexión desde la evolución legislativa y jurisprudencial. En Espacio público y privatización del conocimiento. Estudios sobre políticas universitarias en América Latina. Buenos Aires: Consejo Latinoamericano de Ciencias Sociales, CLACSO.

Yúdice, G. (2002). El recurso de la cultura. Barcelona: Gedisa.

Zizek, Slavoj (2001) El espinoso sujeto. El centro ausente de la ontología política. Buenos Aires: Paidós.

(2004) Violencia en acto. Buenos Aires: Paidós.

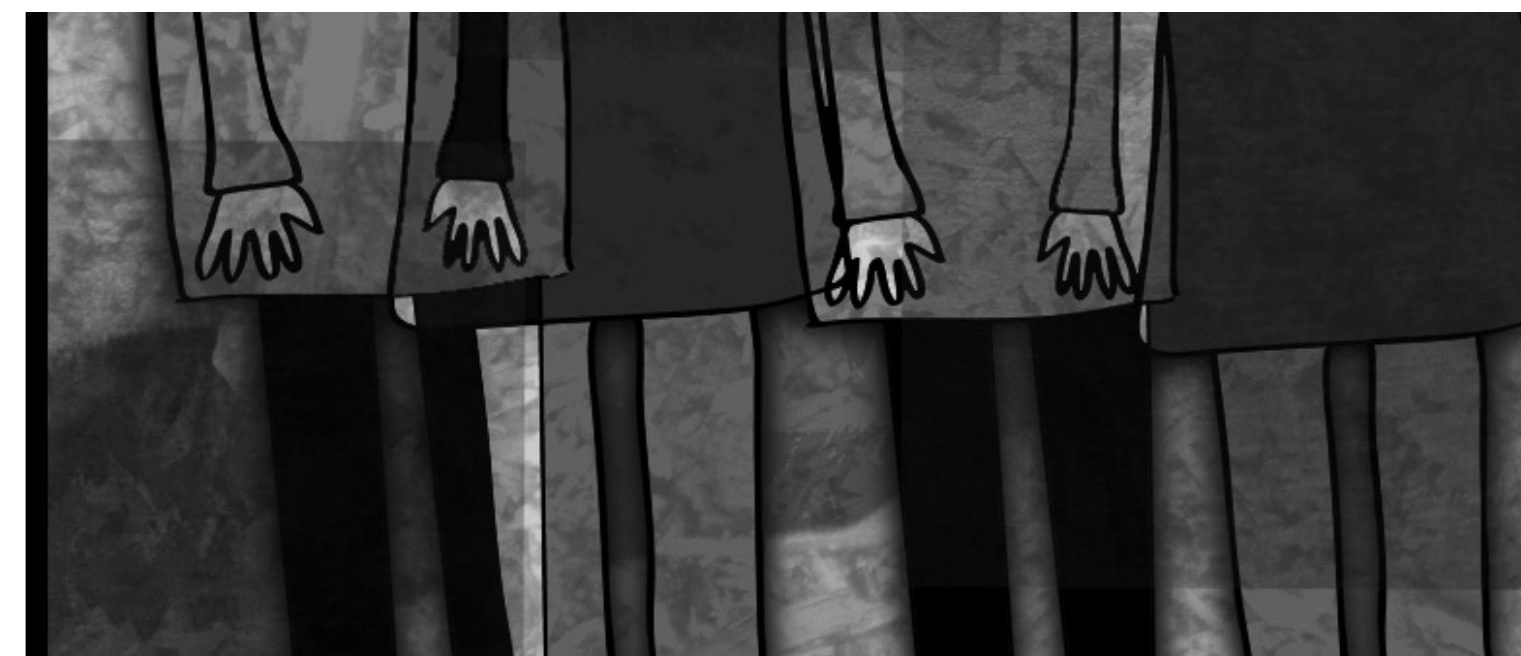

